\title{
OUTROS TEMAS \\ Crianças e Mídias Digitais: um diálogo com pesquisadores
}

\author{
Carla Cristiane Loureiro' \\ Rita de Cássia Marchi"
}

'Universidade Federal de Santa Catarina (UFSC), Florianópolis/ SC - Brasil "Universidade Regional de Blumenau (FURB), Blumenau/SC - Brasil

RESUMO - Crianças e Mídias Digitais: um diálogo com pesquisadores ${ }^{1} \mathrm{O}$ artigo debate a relação das crianças com as mídias digitais, propondo uma visão não alocada no modo determinista e polarizado no qual esta discussão vem sendo realizada. O problema é apresentado de ângulo não usual na literatura brasileira, deslocando o olhar dos riscos para aquilo que as crianças, efetivamente, fazem com as mídias. Estão em diálogo a literatura, trechos de entrevista com a pesquisadora Dra. Cristina Ponte (coordenadora da equipe portuguesa do EU Kids Online), e dados quantitativos e qualitativos sobre o fenômeno. Como resultado, surge a importância de pesquisas feitas com as próprias crianças na construção e interpretação dos dados sobre suas relações com as mídias digitais em diferentes e desiguais contextos sociais e culturais.

Palavras-chave: Crianças. Estudos Sociais da Infância. Mídias Digitais.

ABSTRACT - Children and Digital Media: a dialogue with researchers. The article discusses the relationship of children with digital media, proposing a view, which is not allocated to it on the deterministic and polarized mode in which it has been done. The problem is presented from an unusual angle in the Brazilian literature, shifting from the view of risks to what children actually do with the media. Are in discussion the literature, excerpts of interviews with researcher Dr. Cristina Ponte (coordinator of the Portuguese team of EU Kids Online), and quantitative and qualitative data on the phenomenon. As a result, arises the importance of research done with children themselves in the construction and interpretation of data about their relationships with digital media in different and unequal social and cultural contexts. Keywords: Children. Childhood Social Studies. Digital Media.

Educação \& Realidade, Porto Alegre, v. 46, n. 1, e98076, 2021. 


\section{Introdução}

Atualmente, parece não haver dúvidas de que as mídias digitais impactam a vida das crianças devido à grande atração e prazer que elas sentem na experiência com as tecnologias virtuais, convergentes, móveis e interconectadas. Assim, a relação entre crianças e mídias tem fomentado a produção de pesquisas que analisam esse complexo tema. Mas, no debate acadêmico, posições a favor e contra têm mobilizado ideias paradoxais sobre estas duas categorias (crianças e mídias digitais), evidenciando a circulação dessas diferentes e polarizadas visões também no contexto social mais amplo.

É importante salientar que o debate acadêmico em torno do tema da relação das crianças com as mídias tem sua origem nas incertezas e transformações sociais mais amplas que, no contexto da nossa modernidade tardia, atingem as diversas instituições sociais e, assim, alteram também as relações intergeracionais. De acordo com Sarmento (2011), são mudanças que ocorrem nas práticas sociais das crianças e adultos, bem como nos padrões de interação entre ambos; mudanças no estatuto da infância face às famílias, à escola e às demais instituições sociais, sendo que a teorização sobre este fenômeno tem sido realizada tomando, frequentemente, como ponto de partida, os efeitos das tecnologias de informação e comunicação sobre as crianças. Portanto, este é um debate que se coloca no centro das preocupações educativas.

O objetivo deste artigo é apresentar e discutir as compreensões correntes neste debate, propondo uma visão que não esteja alocada numa forma determinista e polarizada em dicotomias. Assim, a proposta é apresentar o problema por um ângulo ainda pouco usual na literatura brasileira, mas que tem sido o modo inovador como pesquisadores anglófonos têm abordado o tema, pois deslocam o olhar dos riscos (a criança em perigo ou perigosa) para aquilo que, efetivamente, as crianças fazem com as mídias (cf. Buckingham, 2007, 2010; Livingstone, 2011, 2014,2015 , entre outros). Isto é, para estes autores, como forma de saber o que as crianças realmente fazem com as mídias digitais e vice-versa, são necessárias pesquisas empiricamente fundamentadas que examinem como este grupo diversificado de atores sociais usa essas ferramentas em diferentes contextos.

Para o alcance do objetivo deste artigo são mobilizados alguns dados quantitativos, a literatura da área e trechos de uma entrevista (realizada pelas autoras deste artigo) com a pesquisadora Prof. Dra. Cristina Ponte ${ }^{2}$. Esta especialista é vice coordenadora do Grupo Children, Youthand Media, da European Communication Research and Education Association (ECREA) e, desde 2006, coordenadora da equipe portuguesa de pesquisadores do EU Kids Online, que investiga os usos que as crianças fazem da internet e a mediação de suas famílias, reunindo dados de 33 países europeus ${ }^{3}$. A decisão de utilizar trechos da entrevista realizada com a pesquisadora portuguesa visa incutir um perfil mais dinâmico tanto ao material de cunho bibliográfico comumente utilizado em artigos acadêmicos, quanto ao próprio material da entrevista 
que, ao não ser apresentado de forma monolítica e na íntegra, como de costume, dinamiza a discussão travada neste texto através de reflexões e dados atualizados sobre o tema em foco.

\section{Os Termos do Debate Acadêmico - riscos reais e imaginados}

No debate, por um lado temos os chamados utópicos que celebram o comando, pelas crianças, de uma tecnologia que é vista como parte importante do futuro. Esta posição baseia-se em suposições sobre a capacidade natural das crianças em aprender habilidades técnicas. Por outro lado, os chamados pessimistas argumentam que a competência das crianças para usar as mídias digitais tanto pode as colocar em perigo quanto torná-las perigosas.

Essas interpretações contrastantes são ambas problemáticas. Isto porque se baseiam numa visão essencialista da infância que se fundamenta em sua suposta natureza biológica. Nesse sentido, tanto a compreensão dos utópicos quanto a dos pessimistas está fundamentada na ideia de uma infância natural (isto é, universal). Ou seja, as duas posições, embora concebam a infância como uma construção social e histórica (portanto, susceptível às mudanças no tempo) parecem, ao mesmo tempo, desconsiderar o caráter relacional e historicamente construído do fenômeno, pois recorrem - paradoxalmente - à ideia de uma criança essencial para justificar seus argumentos ${ }^{4}$. Esse essencialismo, como se sabe, não é novo, sendo inerente à ideia de infância tal como foi socialmente construída na modernidade e que, por isso, tem sido dominante nas sociedades ocidentais desde o Iluminismo (Marchi, 2007).

Assim, os discursos dominantes acionam representações culturais e históricas sobre a infância, onde as crianças são representadas de formas diversas e, muitas vezes, antagônicas: ora como naturalmente inocentes e vulneráveis, ora como ardilosas e precisando de controle ou, ainda, como sábias e empoderadas. Portanto, concorda-se com Buckingham (2007, p. 119) quando afirma que "[...] os termos do debate estão equivocados. Considerar que as crianças sejam vítimas passivas da mídia ou consumidoras ativas significa efetivamente vê-las como isoladas dos processos de mudança social e cultural mais amplos”.

As compreensões de infância e de mídia que estão, por exemplo, na base do argumento dos pessimistas - a criança em perigo ou a criança perigosa - têm uma longa genealogia no pensamento ocidental, como Sarmento (2007), baseado em James, Jenks e Prout (1998), indica:

[...] a criação de sucessivas representações das crianças
ao longo da História produziu um efeito de invisibilização
da realidade social da infância. Esse trabalho de 'imagi-
nação' da infância estruturou-se segundo princípios de
redução da complexidade, de abstração das realidades e
de interpretação para fins normativos da criança 'ideal'
[grifo no original] (Sarmento, 2007, p. 28).

Neste sentido, os conceitos de infância e criança são o resultado histórico de uma complexa rede de inter-relações entre a ideologia, o 
Estado, as ciências biomédicas, a filosofia, a pedagogia e a tecnologia, em que cada um destes domínios tende a reforçar os demais, desenvolvendo-se de forma diferente e em diferentes velocidades nos diversos contextos nacionais (Buckingham, 2007). Portanto, há uma pluralidade de infâncias e de discursos que as definem. Mas, na medida em que a experiência infantil é essencializada e delimitada à diferença que guarda das experiências dos adultos, ou seja, na medida em que é limitada ao viés geracional, o sentido implícito é o da homogeneidade. Isto ocorre quando, por exemplo, se diz que todas as crianças gostam de videogames e que sabem jogar melhor que os adultos. Essas ideias "[...] refletem um sentimentalismo sobre as crianças e jovens que deixa de reconhecer a diversidade das experiências vividas na infância, assim como das relações das crianças com as mídias” (Buckingham, 2007, p. 87).

Esta homogeneidade, implícita nos discursos utópicos e pessimistas, oculta os desiguais mundos sociais ${ }^{5}$ das crianças que são fraturados por outras variáveis além da geracional, como as diferenças de classe, gênero e etnia. Além disso, a suposição de que as crianças são "[...] componentes acessórios ou meios da sociedade dos adultos" (Sarmento; Pinto, 1997, p. 10), cujo comportamento dominado por tendências naturais necessita ser moldado, acaba por lhes negar o estatuto de atores sociais.

Outro problema é que estas interpretações sobre a relação das crianças com as mídias digitais são tecnologicamente deterministas, pois, de certa forma, assumem que a tecnologia não é controlada pelos indivíduos e sim que esta os controla, isto é, que ela molda a sociedade às exigências de eficiência e progresso. Via de regra, este ideário determinista defende que a tecnologia espelha "[...] o avanço do conhecimento do mundo natural para servir às características universais de natureza humana, tais como as necessidades e faculdades básicas" (Feenberg, 2003, p. 7). Tais interpretações assumem, portanto, que a tecnologia é uma entidade estável que impactará e mudará a sociedade de formas positivas ou negativas - predeterminadas.

Este debate parece poder ser sintetizado na frase "[...] parecemos não saber mais onde encontrar a infância” (Buckingham, 2007, p. 15), na medida em que a ideia de infância tem sido relativizada tanto no senso comum quanto nos discursos acadêmicos. (Marchi, 2007). Notadamente, o discurso sobre as habilidades naturais das crianças para lidar com as mídias digitais parece inverter as relações tradicionais de poder que definem as crianças como menos capazes e menos competentes que os adultos, o que gera, por sua vez, deslocamentos na compreensão tradicional que as sociedades têm sobre as crianças e seu lugar na sociedade (Buckingham, 2007).

Deste modo, se destaca nas pesquisas, em geral, uma compreensão alarmista (um tipo de pânico midiático ou pânico moralista) ${ }^{6}$, visão que também não é nova e que vem se repetindo tanto através do tempo quanto através de diferentes contextos culturais. Este entendimento tem uma longa história, sendo 
[...] pelo menos tão antigo quanto o filósofo grego Platão, que propunha banir as obras dos dramaturgos da sua República ideal, por suas influências perniciosas sobre as impressionáveis mentes infantis. Nos tempos modernos, estas ansiedades se misturaram às preocupações mais gerais com o iminente colapso da ordem social ao alcance das 'massas' indisciplinadas - e, em particular, com as tendências criminosas atribuídas aos jovens da classe trabalhadora urbana, especialmente os do sexo masculino. Tais argumentos, assim como as lamúrias generalizadas a respeito da 'morte da infância', são muitas vezes motivadas pela nostalgia de uma Idade de Ouro imaginária que sempre parece ter existido duas gerações atrás (Buckingham, 2007, p. 179-180).

Assim, uma recorrente compreensão que surge no discurso pessimista sobre a relação das crianças com as mídias digitais é o risco do contato com a violência e o sexo que, entre as muitas experiências que as mídias podem oferecer às crianças, tem sido visto como o único que precisa ser enfocado. Esta preocupação, igualmente, não é nova, pois a televisão já foi acusada de expor as crianças a conteúdos violentos. Os jogos eletrônicos, em especial, por conta de efeitos gráficos cada vez mais realistas, têm sido acusados, no entanto, de causar um tipo de violência imitativa, porque tenderiam a encorajar as crianças a reproduzir determinados atos.

Portanto, à medida que cada novo meio ou forma cultural emerge (rádio, cinema, TV, internet etc.) as mesmas preocupações (re)aparecem. Embora cada pânico possa parecer específico, a recorrência de ansiedades semelhantes pode indicar uma continuidade subjacente mais ampla. $O$ pânico que se estabelece na reflexão sobre a relação das crianças com as mídias parece ser, neste sentido, sempre-e em todos os lugares - o mesmo: a corrupção do ser inocente pela cultura (Loureiro, 2017).

Observados os dados da pesquisa TIC Kids Online Brasil 2015 (CGI.br, 2016), realizada pelo Centro Regional de Estudos para o Desenvolvimento da Sociedade da Informação (Cetic.br) ${ }^{7}$, vê-se que $77 \%$ dos pais consideram que os filhos não passarão por constrangimentos e incômodos na internet, ou que acham pouco provável que isso aconteça. Isto pode indicar que eles têm certa confiança no que as crianças e jovens fazem na rede ou que não percebem nenhum potencial perigo no fato das crianças jogarem online, mesmo com desconhecidos. Mas, este dado, de acordo com os pesquisadores, também pode indicar que os pais pouco sabem sobre as experiências de seus filhos com jogos, uma vez que não há dados qualitativos que interpretem melhor essa questão. Para a pesquisadora Cristina Ponte, este

É um argumento antigo, mas que continua valendo, e isso tem a ver com o fenómeno recorrente do media panics. Sobretudo nos Estados Unidos, um país onde a Associação dos Psicólogos e a Associação dos Pediatras têm muita força, há uma grande tradição de estudos de efeitos, estudos experimentais, realizados em condições de laboratório. É importante 
contrariar essa metodologia e ver como é que as crianças usam jogos que têm um determinado grau de violência, o que é para elas o jogo e o que é para elas a vida real. Quando nós fizemos o questionário, tínhamos uma pergunta aberta, na internet: 'o que é que incomoda as crianças da tua idade'. Nas respostas, vimos que uma coisa que as incomoda muito são os conteúdos violentos baseados em fatos reais. As notícias incomodam mais do que haver um monstro que mata outro, pois isso eles sabem que é ficção. É a mesma coisa com os adultos, o conteúdo dos mídias é violento, isso não quer dizer que toda a gente que vê esses conteúdos sai atirando (Ponte, 2016).

Quando se trata de pesquisas com crianças, o foco tem recaído, portanto, sobre os efeitos das mídias sobre elas e, nesse sentido, estão fundamentadas em “[...] uma forma de behaviorismo ou 'teoria da aprendizagem social' [...] [que buscam] demonstrar conexões causais entre estímulos violentos e respostas agressivas" (Buckingham, 2007, p. 153-154). Assim, as pesquisas acadêmicas sobre o impacto das mídias nas audiências podem ser vistas como uma espécie de pêndulo entre uma mídia poderosa e públicos poderosos (Buckingham, 2007, p. 69).

Com o apoio de pesquisas e de casos midiáticos ${ }^{8}$, o discurso de uma conexão direta entre uma mídia ruim e criminalidade tornou-se parte do senso comum que deixa oculta a discussão da violência como fenômeno complexo que envolve, de maneira mais ampla, questões sociais, econômicas, culturais, políticas e afetivas. Como resultado, tem-se a pressão sobre os legisladores para a criação de diretrizes para produtores, classificação de conteúdos, incremento de ferramentas de filtragem e configurações de privacidade para garantir que crianças não sejam expostas a conteúdos inapropriados.

Na pesquisa realizada pela equipe do EU Kids Online para mapear as preocupações das crianças sobre o ambiente online, o conteúdo violento possibilitado pela internet é uma preocupação mencionada mais por meninos $(21 \%)$ e por crianças menores, contra $16 \%$ das meninas. No entanto, este tipo de conteúdo é somente a terceira preocupação mais citada, ficando atrás do conteúdo pornográfico e dos riscos relacionados à conduta. Os conteúdos violentos que as crianças afirmam ter acesso, na maioria dos casos, são montagens gráficas de sequências descontextualizadas de acidentes, abusos ou mortes, notícias sobre ataques terroristas e assassinatos, além de cenas de sofrimento ou abuso de vítimas vulneráveis como animais, pessoas deficientes e crianças (Livingstone; Kirwil; Ponte;Staksrud, 2014).

Buckingham (2007) salienta, em suas pesquisas sobre a televisão, que, embora as crianças desenvolvam estratégias (se recusar a assistir, se preparar para o conteúdo violento, pensar positivamente) para enfrentar os sentimentos indesejados induzidos por material ficcional, elas geralmente acham mais difícil lidar com a realidade, isto é, com o cotidiano, "[...] justamente porque elas têm tão pouco poder para intervir nos assuntos que lhes dizem respeito" (Buckingham, 2007, p. 197).

Não há dúvidas de que algumas crianças podem desenvolver uma relação não muito saudável com as mídias. No entanto, analisar este 
engajamento apenas pelos riscos potenciais acaba por simplificar esta relação, trazendo à tona velhas imagens advindas de discursos psicologizantes sobre o que é uma criança normal, classificando a participação ativa nas mídias digitais como patológica ${ }^{9}$. Essas imagens e essa narrativa também sugerem que as mídias têm, por si, a capacidade de determinar resultados sociais, acabando por reforçar o que Sarmento (2007, p. 32) definiu como o "[...] encerramento do círculo da negatividade, a ideia de que as crianças atuais vivem, definitivamente, um processo de adultização precoce e irreversível, e, por consequência, habitam a idade da não-infância”. Desta forma,

[...] a infância é analisada a partir de sua imagem arquetípica, conceptualizada como um 'tornar-se' estruturado, e não como uma prática social nem como um lugar para o self (por mais ilusório que o pós-estruturalismo tenha tornado esse conceito). $O$ arquétipo da criança é sustentando na linguagem e nos discursos profissionais, das instituições e das especializações que servem para controlar as fronteiras estabelecidas em torno da criança enquanto estatuto social. Essas fronteiras não se reduzem a traçar limites à criança, pois também interditam um espaço social que, por sua vez e a outro nível, expressa a componente de controlo exercida no quadro desse sistema social e a variante de controlo que revela interesses que sustentam seu funcionamento (Sarmento, 2007, p. 32).

Assim, a criança que, em tese, é também sujeito ativo parece não ocupar o mesmo lugar social do sujeito colaborativo que experimenta, no uso das tecnologias, novos modos de autoria, de subjetivação e de sociabilidade. Portanto,

De certo modo o lugar da criança na cultura naturalizouse na perspectiva da recepção, ainda que se reconheça suas capacidades de contemplação ativa e ressignificação. No contraponto, naturalizou-se também ser o adulto quem produz e apresenta a cultura às crianças. Paradoxalmente, quando a perspectiva da imersão ameaça desnaturalizar esses lugares verticalizados, emerge uma série de discursos sobre a fragilidade infantil e sobre os riscos e perigos que envolvem a relativa autonomia que a experiência imersiva propõe (Pereira, 2013, p. 324).

Além disto, pode-se destacar que as pesquisas que envolvem a relação das crianças com as mídias e que discutem sobre os tipos de jogos e a quantidade de tempo que as crianças gastam com eles, têm revelado que, muitas vezes, famílias, educadores e demais adultos, apresentam uma visão romântica do espaço virtual como um espaço livre, assim como uma visão igualmente idealizada do espaço real como mais autêntico ou mais saudável para as crianças (Valentine; Holloway, 2002). No entanto, são poucos os trabalhos que se dedicam a compreender como, efetivamente, as crianças usam as mídias digitais (Loureiro, 2017). 


\section{Mudança de Paradigma nas Pesquisas - o que efetivamente as crianças fazem?}

Com a atenção agora voltada ao deslocamento que alguns pesquisadores infligem ao debate tradicionalmente baseado em visões polarizadas e eivadas de essencialismos, vai-se considerar trabalhos que fornecem pistas de como as crianças negociam relações sociais online (cf. Turkle, 1997). Isto é, vai-se considerar estudos que têm se dedicado a superar a visão centrada apenas nos riscos e perigos a que as crianças se expõem ou aos quais são expostas no contato com as novas mídias.

Tendo em vista essa questão, e o fato da Convenção sobre os Direitos da Crianças, de 1989, incluir os direitos de comunicação e de participação (artigos $12^{\circ}$ a $17^{\circ}$ ) ao lado dos direitos de provisão e de proteção, foi perguntado à pesquisadora Cristina Ponte de que maneira os dados acumulados nos projetos Kids Online podem contribuir para que as crianças não sejam vistas como estando somente $\mathrm{em}$ risco na internet. A isto, ela respondeu que:

[...] quando o projeto [EU KidsOnline] começou, ele era financiado pela Comissão Europeia num programa que se chamava Safer Internet Plus, portanto o foco estava na segurança, e isso marcou a primeira pesquisa. No desenho da pesquisa que estamos a fazer, sem deixar de lado a questão do risco, nós queremos também prestar atenção nas capacidades, nas atividades criativas das crianças, como a experiência da internet tem impacto no seu bem-estar. [...] Para cobrir estes pontos, é preciso pesquisa qualitativa também. Neste momento a discussão que nós fazemos tem um enquadramento teórico que foca na perspectiva dos direitos digitais e do bem-estar, como é que a experiência da internet e do digital marca o bem-estar da criança? Isso é uma coisa que nós queremos responder (Ponte, 2016).

Assim, percebe-se que, sem deixar de lado as questões ligadas ao risco dos usos da internet pelas crianças, os pesquisadores do projeto EU Kids Online vêm redesenhando as pesquisas para também captar, de forma qualitativa, capacidades, atividades criativas, e os modos como a experiência da internet têm impacto no bem-estar das crianças. Isto é, se num primeiro momento do projeto o foco estava na segurança das crianças, sem deixar este aspecto de lado, os pesquisadores agora prestam atenção nas capacidades e nas atividades criativas das crianças, buscando compreender de que maneiras a experiência da internet tem impactado no bem-estar deste grupo social. Pode-se objetar aqui que, certamente, a segurança é um dos componentes essenciais ao bem estar dos indivíduos (quaisquer que sejam suas idades), mas o que a pesquisadora pretende destacar, em sua resposta acima, é a ampliação do foco dos estudos para aspectos até então negligenciados nas pesquisas e que, igualmente, constituem o chamado bem estar das crianças.

Nesse sentido, usar metodologias qualitativas centradas nas crianças e elaboradas para reconhecer suas vozes e experiências com as mídias digitais é fundamental para o avanço das pesquisas na área, “[...]tanto porque suas preocupações são diferentes daquela dos adultos, 
quanto porque os relatos das crianças oferecem compreensões valiosas sobre as condições das suas angústias" (Livingstone; Kirwil; Ponte; Staksrud, 2014, p. 93-94).

No Brasil, as pesquisas realizadas pelo Cetic, também fornecem bons dados para análise, mas, geralmente, estas são realizadas a partir de questões fechadas em áreas de interesse político já estabelecido, como a segurança na internet ou o consumo.

Se algumas pesquisas têm sido realizadas fora do ambiente escolar (Valentine; Holloway, 2002; Livinstone; Mascheroni; Dreier; Chaudron; Lagae, 2015), a maior parte dos estudos sobre como as crianças jogam em contextos domésticos foi principalmente realizada por meio de entrevistas e questionários com crianças e pais, assim como boa parte focaliza os jogos de computador em si, destacando as estruturas e regras e as possibilidades de aprendizagem (Gee, 2003; Prensky, 2010). Ou seja, o foco dos estudos não está centrado nas vozes e interpretações das crianças sobre como elas se relacionam com as diferentes mídias e nem nas formas dessa relação.

Outro fator relevante é o crescimento da conexão por meio de celulares, que tem sido destaque nas pesquisas nos últimos anos. Em 2012, 21\% das crianças e adolescentes brasileiros acessavam a internet por telefone celular, em 2014 o número subiu para $82 \%$ e em 2015 para $85 \%$. Um em cada três jovens (31\%) usa exclusivamente o celular para se conectar (CGI.br, 2016). Em 2017, 93\% dos usuários de Internet de 9 a 17 anos se conectaram por meio do telefone celular, o que equivale a mais de 23 milhões de crianças e adolescentes (CGI.br, 2018).

Estes dados sobre o acesso de crianças e jovens à internet quase exclusivamente através de celulares requerem estudos mais aprofundados para que se possa verificar como se articula o conhecimento das crianças adquirido nas mídias ao processo educativo formal. Isto porque, pesquisas tanto no Brasil como em Portugal apontam que as crianças e jovens, com frequência, utilizam os celulares em contextos informais de aprendizagem, recorrendo a diferentes funções, produzindo diversos tipos de mídia, interagindo nas redes sociais e isto, muitas vezes, de forma colaborativa. No entanto, a escola permanece como, talvez, um dos últimos redutos na resistência à utilização dos celulares no meio educativo formal. Pois, sabe-se que estudantes e professores usam celulares dentro e fora do ambiente escolar, mas atividades realizadas nas salas de aula utilizando esta tecnologia são ainda muito pouco frequentes (CGI.br, 2018). Além disso, se, por um lado, os celulares proporcionam às crianças acesso a serviços e informações, além de funcionar como ferramenta que reduz as distâncias entre amigos e familiares, por outro lado, o uso quase exclusivo do celular pode mascarar as desigualdades de estímulos e oportunidades se compararmos com dados sobre crianças e jovens que têm acesso a diferentes meios tecnológicos.

Estudos desenvolvidos no contexto europeu indicam também que o uso de celulares aliados à rede WiFi, além das redes $3 \mathrm{G}$ e $4 \mathrm{G}$, parece propiciar às crianças a sensação de ter a Internet de forma onipresente e ilimitada, como destaca a pesquisadora: 
Outra coisa que marca muito é a pressão para estar sempre ligado. Um dia destes, vi um vídeo de uma investigadora norte-americana que construiu com as crianças (de 11 e 12 anos) uma identificação dos problemas que elas tinham na internet, para depois encontrarem soluções; uma das coisas que eles sentiam eram os mal entendidos que decorriam do fato de eles não responderem imediatamente a uma mensagem que tivessem recebido. Se não responde de imediato, a pessoa que enviou a mensagem, pensa: não quer responder! Mas, as vezes a pessoa não está perto do telefone e criam-se aqui interpretações errôneas, mal entendidos, falsas expectativas. Uma das coisas que em 2014 apareceu com intensidade, era o número de jovens que diziam ter dificuldade em não estar a olhar para o telemóvel, sofrendo ansiedade: o que que eu estou a perder se não estou... Sem dúvida que a tecnologia marca, mas não é um efeito único para todos; também é preciso ter em conta se a criança tem uma boa autoestima, se tem capacidade de dizer: não quero estar sempre ligado. Mas sem dúvida que as crianças de hoje que têm acesso a esses meios, estão crescendo em condições que são diferentes, das condições em que cresceram os seus pais (Ponte, 2016).

A fala desta pesquisadora coloca em questão uma das práticas mais importantes na vida das crianças: estar com os pares. As mídias digitais impactam fortemente esta prática, uma vez que, por meio delas, as crianças podem estar em contato (quase ininterrupto) com seus amigos através das redes sociais, de aplicativos de mensagens e de jogos online. Assim, o que acontece quando o acesso às redes sociais e às mensagens instantâneas ocorre pelos celulares, que agora estão sempre à mão? O potencial para contatar ou encontrar com amigos a toda a hora, em qualquer lugar tem gerado novas preocupações e ansiedades sobre o fato e a possibilidade (ou necessidade) de estar sempre online. Aqui se coloca também o desafio de saber buscar um equilíbrio entre a privacidade e a exposição; lembrando que este, na verdade, é um desafio que se coloca atualmente também para adultos.

As pesquisas realizadas no Brasil e em Portugal indicam que as diferenças entre as crianças (diferenças sociais, etárias e de gênero) também alteram significativamente sua relação com as mídias digitais, ou seja, as formas de acesso e de uso. Na questão social, destaca-se que o aumento do número de crianças que têm seu próprio celular potencializa usos mais intensivos de jogos online (Vincent, 2015). Além disto, a cultura do quarto (Bovill; Livingstone, 2001) é sustentada e reforçada na medida em que a criança não precisa mais sair do quarto e do conforto de sua cama para assistir TV, jogar, usar computador ou mesmo falar com alguém em sua casa. No entanto, a pesquisadora C. Ponte esclarece que o aumento do número de crianças de posse de um celular precisa ser relativizado:

Esse aumento no uso de smartphones mostra bem como as indústrias estão a promover o acesso dos jovens à internet pelo celular. Mas, se esse é um número impressionante, se formos ver em que condições acessam, como é o pacote de internet, se tem wi-fi ou não, aí vemos as restrições. Um jovem que tem apenas um celular tem poucas opções, pois ter um portátil, ou mesmo ter um computador de mesa, ou tablet dá outras possibilidades de uso [...]. 
Sem dúvida que a questão da classe social, ainda mais num país como o Brasil, é imensa e marcante. Quando perguntamos: você acessa a internet pelo smartphone? Não há grande diferença de classe, a questão é os meninos de classe elevada têm smartphone, têm portátil, têm PC, têm console... Enquanto os outros têm um celular ou um smartphone que muitas vezes, só permite o acesso ao Facebook e ao Instagram, estão canalizados para usar só isso. Muitas vezes não tem wi-fi, tem que ter o acesso por 3G que é mais caro e muitas vezes restringe o tempo de uso (Ponte, 2016).

Para esta pesquisadora, a questão do gênero tem também destaque, sendo marcada pela diferença das atividades realizadas por meninas e meninos na internet, nos diferentes países. Ela informa que, para além do projeto EU Kids Online e Kids Online América Latina, há ainda outros países participando de um projeto da UNICEF, o Global Kids Online, que possibilita a ampliação de dados sobre contextos sociais e culturais não contemplados nos dois primeiros projetos. Assim sendo, a pesquisadora afirma que:

O gênero, sobretudo, é muito marcado na diferença das atividades que eles e elas fazem, nos diferentes países (neste momento além do EU Kids Online e Kids Online América Latina, há outros países participando de um projeto da UNICEF, o Global KidsOnline ).

Uma das coisas que esse contato com pesquisadores de diferentes países tem mostrado é que se, em muitos países não há grande diferença de gênero na maneira que os pais tratam os meninos e as meninas no acesso à tecnologia, em muitos outros essa diferença é abissal. Por exemplo na Turquia, no estudo de 2010, quando o pesquisador chegava na casa e perguntava: quantas crianças há nessa casa? O pai e a mãe diziam: há duas. Passado um tempo, o entrevistador percebia que na verdade havia 5 crianças, eram dois meninos e 3 meninas. Os resultados no Brasil mostram que não há diferenças de gênero em relação à posse [dos equipamentos], mas há diferenças no uso e um pouco na mediação dos pais. Mas essa questão é daquelas que só se podem captar bem numa pesquisa qualitativa (Ponte, 2016).

Nos jogos e na internet, em geral, o sexo é tratado como diversão e as mulheres como objetos (Lara Croft, por exemplo, de forte apelo sexual, é uma das poucas protagonistas femininas em jogos eletrônicos). Ao mesmo tempo, existe hoje um discurso de empoderamento feminino (difundido largamente nas redes sociais). Assim, as crianças e os jovens percebem muitas vezes contradições entre o que ouvem e o que observam na vida em sociedade. Desse modo, perguntamos à pesquisadora Cristina Ponte, como ela percebe os sentidos que as crianças constroem com relação à sexualidade e às relações de gênero em meio a mensagens potencialmente contraditórias. A isto ela respondeu que:

Um exemplo paradoxal de um país com uma forte dimensão conservadora são os concursos de beleza infantil nos Estados Unidos Esses concursos são ao vivo, em direto, passam na televisão, com meninas hipersensualizadas. A sexualização das crianças, em especial as meninas é uma realidade que corresponde a pulsões, a desejos de patriarcado, há toda uma cultura patriarcal em que os mídias estão inseridos. Pensar que são os mídias os únicos responsáveis por isso, é ignorar todo um contexto, 
que é um contexto em que essas questões em uma sociedade de consumo, hedonista, estão muito intensificadas. Há alguns programas e políticas que procuram contrariar o fosso entre as meninas e a programação de jogos, exatamente intensificando programas que correspondam aos interesses delas e que as capacitem para programar (Ponte, 2016).

Em pesquisa sobre conteúdos destinados ao público infantil, através de sites de jogos de meninas e de meninos, Felipe (2012) procurou ver o que eles veiculam em relação às narrativas sobre relações de gênero e sexualidade. Os resultados apontaram que, no caso de sites direcionados às meninas, a ênfase está em atividades voltadas ao culto e embelezamento do corpo, aos cuidados da casa e à busca do par perfeito. Já, para os meninos, as atividades compreendem jogos de ação e velocidade e os que estimulam o raciocínio lógico-matemático. Para esta autora, enquanto artefatos culturais, os sites (re)produzem uma visão extremamente binária, em que meninos e meninas, homens e mulheres, seguem em mundos completamente separados (Felipe, 2012). Isto é, foi detectada uma linguagem sexista, com estabelecimento de padrões heteronormativos. Aqui, portanto, vai-se ao encontro do que a pesquisadora Cristina Ponte afirma acima: as mídias certamente reproduzem o sistema patriarcal no qual estão inseridas, mas atribuir a elas a conformação deste sistema seria não somente indevido, como também insensato.

Finalizando sua compreensão sobre a relação entre classe social ${ }^{10}$, gênero e sociabilidade das crianças, a pesquisadora Cristina Ponte considera que:

[...] essa experiência de estar online todo o tempo não pode deixar de ter relação com a sociabilidade das crianças. A equipa da Inês Vitorino, de Fortaleza [CE, Brasil] fez uma pesquisa com grupos focais com crianças de 11 e 12 anos de nível classe média, média alta e classe baixa. Essa pesquisa revelou como elas vivem... e aqui sobretudo tem uma diferença de gênero, em especial nas meninas da classe média alta, que ficam todo tempo na rede, todo tempo conectadas, fazendo todo tipo de atividades, vendo filmes, conversando. Há até uma expressão para isso: 'Gente, vamos madrugar!!!', e o que é madrugar? É à meia-noite todos da sua cama enviando mensagens uns para os outros, a verem filmes em conjunto e comentando, e é toda uma intensificação dessa partilha na rede. Outra coisa que também marca muito o uso no Brasil é uma exposição, um culto do corpo e da apresentação, também um culto da popularidade, a captura de curtidas, a pesquisa mostra uma série de experiências da intensificação da exposição, da apresentação do eu, e para analisar isso o olhar de Erving Goffman é inspirador. Como as crianças estão crescendo sempre a se apresentarem aos outros, procurando ter uma boa performance (Ponte, 2016)

As questões apontadas por Cristina Ponte, na fala acima, indicam como o uso do celular pelas crianças tem possibilitado um alargamento e/ou criação e combinação de suas práticas ou repertórios de comunicação (Haddon, 2004) com os pares, e também com outras audiências (por meio das redes sociais e até dos seus canais no YouTube). Assim, pode-se fazer alguns questionamentos: será que as crianças estão de- 
senvolvendo novas noções sobre amizade e sobre diferentes regimes de privacidade, a partir das formas de comunicação e interação nas redes sociais, plataformas e aplicativos?

Observando os fatos também pelo prisma das diferenças de idade entre as crianças, observa-se que os discursos correntes acerca do $\mathrm{na}$ tivo digital ${ }^{11}$ - com capacidade natural para lidar com as novas mídias - não se sustentam ante as práticas de algumas crianças (mais jovens e/ou com pouco acesso às tecnologias) que expressam receio de errar ou mesmo de não dominar os códigos da cultura digital, especialmente diante dos pares (Loureiro, 2017).

\section{Relações Intra e Intergeracionais com as Mídias Digitais - o brincar e o aprender}

Para compreender as relações entre adultos/crianças e entre crianças/crianças quando relacionadas às experiências com as mídias digitais, não deveríamos ver apenas mudanças nas gerações ao longo do tempo, mas sim as

[...] relações invisíveis, diretas e indiretas, por intermédio das quais as crianças se incorporam firmemente em conjuntos estruturados de relações sociais mais amplas do que suas relações locais muito imediatas e potencialmente extensíveis ao sistema social global. (Alanen, 2001, p. 142, tradução das autoras).

Ou seja, há de se considerar os impactos da noção de geração, já que a infância, enquanto categoria estrutural da sociedade, “[...] tanto se transforma de maneira constante assim como é uma categoria estrutural permanente pela qual todas as crianças passam” (Qvortrup, 2010, p. 637, itálico no original).

Dados da pesquisa do Cetic.br apontam que entre jovens de 11 a 17 anos, $46 \%$ afirmaram saber muitas coisas sobre como usar a Internet e $70 \%$ acreditam saber mais que seus pais sobre Internet. Nesse caso, a mediação parental merece atenção, em especial quando somente 50\% dos pais são usuários. A partir desse panorama, perguntamos à pesquisadora Cristina Ponte como avalia que deva ser a atitude dos pais frente às formas como os filhos usam os dispositivos digitais:

Não se pode generalizar. É muito diferente pensar em países como Portugal e o Brasil, onde a penetração da internet entre pais é mais recente, e pensar em países como a Noruega, onde os pais e os avós já usam, e muito, a internet há muitos anos.

Uma pesquisadora norte-americana, Lynn Schofield Clark, tem trabalhado a questão de como os pais podem ser trazidos para o digital e como podem lidar com o desafio do digital. Ela diz que esta situação dos pais não usarem pode proporcionar um ambiente novo de mediação que é um ambiente de aprendizagem em conjunto. Os filhos ensinarem os pais e os pais virem a aprender com os filhos os aspectos técnicos; ao mesmo tempo os pais podem se dar conta de certas situações que os filhos não têm consciência, questões sociais, como por exemplo, mandar uma men- 
sagem que pode ofender o outro. Pode haver aqui uma aprendizagem conjunta, principalmente quando as crianças têm 8, 9 e 10 anos, e ainda não são adolescentes e têm uma boa relação com os pais. Os pais podem aproveitar essa oportunidade para fazer coisas em conjunto com os filhos e aprender com os filhos (Ponte, 2016).

Nesse sentido, vários produtos que circulam nas mídias como os videogames, por exemplo, parecem colocar em conflito a retórica do nativo digital (crianças) versus imigrante digital (pais), pois são produtos que atendem a novas formas de endereçamento geracional, na medida em que atraem o interesse das diferentes gerações (Buckingham, 2007).

Por outro lado, o acesso das crianças às mídias digitais, em especial aos jogos eletrônicos em ambientes familiares, é circunscrito a várias restrições (tempo para jogar, acesso limitado a senhas etc.). Além disso, computadores em casa são frequentemente vistos como ferramentas para auxiliar no aprendizado escolar, pois mesmo quando as crianças jogam, os pais “[...] tentam incorporar essa atividade em um quadro discursivo que conceitua o uso dos computadores pelas crianças em relação à aquisição de habilidades em tecnologia a serem usadas no futuro" (Facer; Furlong; Furlong; Sutherland, 2001, p. 102).

Buckingham (2007) aponta que, nos últimos 50 anos, o tempo e os espaços de lazer das crianças foram sendo privatizados e cada vez mais submetidos à supervisão dos adultos. Assim, o principal lugar para diversão das crianças foi deslocado dos espaços públicos (ruas, praças e parques) para as casas (de início para a sala de estar e, em seguida, para os quartos). A ansiedade sobre a violência das cidades e o medo dos estranhos levaram as famílias a equipar os quartos das crianças como local seguro de diversão.

Neste contexto, as atividades das crianças com as mídias digitais funcionam como uma forma de edutenimento ou curricularização da vida familiar, em que o lazer é transformado em atividades educacionais (Buckingham; Scanlon, 2004) e, portanto, produtivas, o que coloca em ação o discurso da infância como vulnerável e o da criança como aprendiz/aluno, inclusive em casa. Desta forma, a imagem de uma criança ou um jovem sozinho, trancado no quarto, por horas, com seu celular, console ou computador, permite compreender os discursos apocalípticos que reverberam nas mídias e incidem diretamente nas falas e atitudes dos pais quando o assunto são as mídias digitais. Contudo, pesquisar efetivamente o que essas crianças e jovens estão fazendo com seus dispositivos pode trazer novas lentes para a questão.

Os limites estabelecidos para o uso das mídias digitais em casa, juntamente com a valorização de uma retórica do vício e da violência, parecem impedir a análise das mídias como também importantes na vida das crianças. Essas ideias reproduzem apenas a oposição entre brincar e aprender, posicionando a brincadeira ao lado do prazer e do tempo presente das crianças e o aprendizado ao lado do trabalho e das aspirações para o futuro. Assim, as possíveis aprendizagens e habilidades das crianças com as mídias digitais são ignoradas porque vistas como apenas divertimento, já que o jogo “[...] tomado em um sistema 
semântico que o opõe ao trabalho e, portanto, à seriedade e à utilidade, [...] não pode acolher nenhum dos valores que pertencem ao universo ao qual ele justamente se opõe" (Brougère, 1998, p. 201).

Portanto, as únicas habilidades que tais discursos dicotômicos conferem às crianças estão restritas ao domínio de atividades pouco valorizadas socialmente, como jogos, música e atividades imaginativas. Tais habilidades são "[...] consideradas como menor, sem valor sério para os adultos, quando não são invejadas de maneira nostálgica” (Livingstone, 2011, p. 13). Então, até mesmo quando as crianças são compreendidas como empoderadas, estão restritas às características e atribuições conferidas ao chamado ofício de criança ${ }^{12}$.

A fim de destacar também as tendências presentes na produção sistematizada do conhecimento sobre infância, crianças e jogos eletrônicos, apresenta-se agora um levantamento realizado nas revistas $\mathrm{Ga}$ mes and Culture, Children \& Society e Childhood ${ }^{13}$, sobre o tema.

À exceção da revista Games and Culture (que disponibiliza artigos apenas a partir de 2006), as outras duas revistas publicam artigos desde o final da década de 1980; mas, apesar dos jogos eletrônicos fazerem parte da vida das crianças e jovens há cerca de 40 anos, só existe uma pesquisa localizada na década de 1990, enquanto outras surgiram somente a partir do ano 2000. Isso indica que a academia só passou a considerar essa temática como relevante a partir do início do século XXI. Indagada a este respeito, a pesquisadora entrevistada considerou que esta escassez de pesquisas deve ser analisada levando-se em conta também a forma como, historicamente, a Sociologia da Infância tratou as mídias e como a Sociologia das Mídias lidou com as crianças.

Noto que essas são duas revistas da área da Sociologia da Infância [Children \& Society e Childhood,] e durante muito tempo a Sociologia da Infância deu pouca atenção ao mídias. Temas como as condições sociais da infância, o trabalho infantil, a economia, os cuidados de assistência e saúde, portanto a criança na sociedade é muito o foco, em especial da Children \& Society, ou a análises às culturas da infância, ao brincar. Eu diria que talvez já tenha se começado, mesmo que lentamente, a considerar que não se pode perceber a infância sem considerar a dimensão dos mídias, elas estão brincando lá. Mas, se a Sociologia da Infância não fala muito dos mídias, a sociologia dos mídias também quase não fala de crianças. Por isso é importante contrariar essas duas tendências, mostrando que a Sociologia da Infância precisa considerar os mídias e a sociologia dos mídias precisa considerar as crianças (Ponte, 2016).

Em sua resposta, Cristina Ponte destaca a tendência destas duas disciplinas ignorarem-se mutuamente, ou seja, destaca a falta de diálogo entre dois campos que já deveriam estar levando em conta, em suas pesquisas, a presença massiva das crianças no mundo das mídias digitais. Como ressalta a pesquisadora, "não se pode perceber a infância sem considerar a dimensão dos mídias, [pois] elas estão brincando lá”. 


\section{Considerações Finais}

As pesquisas sobre crianças e infância têm registrado, nos últimos anos, significativos investimentos que decorrem de um movimento de reconceitualização dessas categorias que se ancora, especialmente, nos princípios de considerar as crianças como atores sociais e a infância como grupo geracional com direitos, criando e também sublinhando, assim, a necessidade de desenvolver formas de investigação em que sejam levadas em consideração as vozes das crianças na interpretação de suas ações.

Ante o exposto nesse artigo, percebe-se, no entanto, que ainda são desenvolvidas pesquisas com concepções epistemológicas que ignoram as interpretações das crianças para a construção de um conhecimento que não seja somente sobre elas, mas construído com a sua participação. Importante destacar que não se trata de uma mudança que visa apenas emancipar socialmente as crianças de um papel social historicamente submisso, mas de levar em conta o fato de que os argumentos políticos e éticos acerca do direito das crianças de serem ouvidas nas pesquisas que as têm por objeto, estão aliados a argumentos sobre as vantagens epistemológicas que essa escuta pode trazer às investigações assim orientadas. Isso decorre da compreensão de que as crianças estão em melhor posição para produzir conhecimento acerca de si mesmas e dos seus pares e de que, portanto, a investigação tem ganhos significativos quando a participação das crianças é solicitada no processo e os seus conhecimentos (visões, perspectivas, pontos de vista) são aceitos como genuínos e válidos (Christensen; Allison, 2005; Fernandes; Marchi, 2020).

Neste sentido, e retomando o objetivo deste artigo, pode-se considerar essa mudança epistemológica uma ação que visa deslocar o debate - sobre a relação entre as crianças e as mídias digitais - das posições deterministas e polarizadas, seja em relação às própria mídias digitais, seja em relação à visão das crianças como apenas vítimas em perigo (receptoras passivas) ou como possivelmente perigosas (porque empoderadas pelas mídias).

Na medida em que se pensa que o uso massivo das mídias digitais é um fenômeno social relativamente novo, que não fez parte da infância da maioria dos pais e professores das crianças de hoje, compreende-se estar diante do desafio de articular, em futuras pesquisas, a produção simbólica das crianças - que se refletem nos seus modos de brincar na contemporaneidade - com as formas e os variados conteúdos a elas especialmente destinados pela indústria cultural na atualidade (Sarmento, 2008). Isto é, se, realmente, os pesquisadores, pais, professores, legisladores, quiserem obter conhecimento sobre as relações e usos que as crianças estabelecem com as mídias digitais, se quiserem saber o que ocorre quando elas as utilizam, é preciso levar em consideração o que as próprias crianças têm a dizer sobre isto.

Além disto, precisamos compreender que as mídias digitais e a internet não podem ser consideradas apenas como ferramentas ou re- 
cursos auxiliares para a educação das crianças, mas como espaços sociais (Pretto, 2017) onde elas circulam, muitas vezes sem conhecer ou aproveitar todas as possibilidades desse universo. Um desafio bem atual para o cotidiano da escola deve ser o da promoção de atividades colaborativas com as mídias digitais de forma que as crianças possam produzir e disseminar conteúdos; e isto na contramão da preocupação em instalar filtros para bloquear aplicativos ou em investir na criação de programas ou softwares educativos, como já foi feito com o livro, por exemplo, que na escola adjetivamos de didático ou com o brinquedo, que se tornou educativo.

Assim, são necessárias pesquisas empiricamente fundamentadas que investiguem o uso das mídias digitais pelas crianças como grupo diversificado (atravessado pelas variáveis de classe, gênero, idade etc.) e nos diferentes e desiguais contextos sociais e culturais. Dessa forma, dar-se-á um importante passo em direção à quebra de visões homogêneas e polarizadas sobre crianças e sobre mídias, visões centradas apenas nos riscos e perigos - presentes tanto no discurso pessimista quanto no otimista - a que supostamente as crianças se expõem ou são expostas no contato com as mídias.

Entende-se que as questões sinalizadas neste artigo evidenciam que os estudos da criança na intersecção com as novas mídias digitais ainda se configura como um campo não consensual e bastante fragmentado. Além disto, indicam, como também apontou em sua entrevista a pesquisadora Cristina Ponte, que se faz necessário o encontro e constante diálogo entre a Sociologia da Infância e a Sociologia das Mídias que, até o momento, têm se mantido relativamente afastadas ou com pouca interlocução sobre este tema tão atual quanto crucial na vida das crianças.

Recebido em 9 de novembro de 2019 Aprovado em 7 de agosto de 2020

\section{Notas}

1 As autoras agradecem à CAPES o financiamento deste artigo através das bolsas de estudo que lhes foram concedidas (bolsa de Doutorado Sandwich- PSDE e bolsa de Pesquisa Pós-Doutoral no Exterior). Além disto, agradecem o financiamento da Universidade Federal de Santa Catarina - UFSC e da Universidade Regional de Blumenau - FURB.

2 Docente do Departamento de Ciências da Comunicação da FCSH, Universidade Nova de Lisboa, Portugal.

3 Há alguns anos, foram também incluídos na pesquisa países não europeus como Brasil, Chile, Austrália, entre outros, e ampliados os objetivos do projeto devido o crescente acesso aos meios digitais e o surgimento de novas plataformas e conteúdos. Assim, nos anos de 2015 a 2018 o projeto aprofundou o conhecimento sobre as condições da infância nas sociedades contemporâneas através da organização de uma pesquisa pan-europeia que integrasse a nova ecologia digital. Cf. Disponível em:<http://www.lse.ac.uk/media@lse/research/EUKidsOnline/Home.aspx>. 
4 Marchi (2007) sinaliza a manutenção da visão essencialista e naturalizada da infância mesmo por parte de autores que consideram o fenômeno como uma construção social e histórica. Neste artigo, parte-se desta mesma compreensão

5 Mundos sociais da infância ou culturas da infância são conceitos gerados pelos estudos sociais da infância, e definem a capacidade das crianças de construir, entre pares, modos de significação do mundo por meio de ações que se diferenciam das adultas.

6 Giddens e Sutton (2016) definem pânico moral como a reação exacerbada da sociedade a um tipo de comportamento assumido como sintomático de um mal-estar que pode ser social ou moral.

7 O Cetic.br, criado em 2015 com a missão de monitorar a adoção das tecnologias de informação e comunicação (TIC), é um departamento do Núcleo de Informação e Coordenação do Ponto BR (Nic.br) que implementa decisões e projetos do Comitê Gestor da Internet do Brasil (Cgi.br). Disponível em: <https://www. cetic.br>.

8 Cita-se o emblemático exemplo do massacre de Columbine em que dois jovens de uma escola de ensino médio no Colorado (EUA), hipoteticamente inspirados no jogo Doom, mataram 12 colegas e um professor, ferindo outras 21 pessoas.

9 Essa visão fica clara quando se observa que, na revisão mais recente (2018) da Classificação Internacional de Doenças da OMS, o gaming disorder (transtorno do jogo) foi classificado como doença.

10 Devido aos limites estabelecidos para este texto, a relação entre o uso de mídias digitais, crianças e classe social não será abordada.

11 As categorias nativo digital e imigrantes digitais são utilizadas para definir, respectivamente, os que já nascem imersos nas tecnologias e os não nascidos na era digital (Prensky, 2001).

12 Os conceitos de ofício de criança e ofício de aluno (intrinsicamente relacionados) devem ser entendidos no quadro interpretativo do paradigma da infância/ criança como construções sociais. Tendo-se dado o encontro destes conceitos em um mesmo meio (a escola), ambos remetem aos processos de invenção e de modelagem de programas, regras, instrumentos e práticas pedagógicas que fazem da escola o lugar, por excelência, da criança (Marchi, 2007).

13 Levantamento realizado por Loureiro (2017), em Tese de Doutorado em Educação.

\section{Referências}

ALANEN, Leena. Childhood as a Generational Condition: children's daily life in a central Finlandtown. In: ALANEN, Leena; MAYALL, Berry (Org.). Conceptualizing Child-Adult Relations. Londres: Falmer, 2001.

BOVILL, Moira; LIVINGSTONE, Sonia. Bedroom Culture and the Privatization of Media Use. Londres: LSE Research Online, 2001. Disponível em: <http:// eprints.lse.ac.uk/archive/00000672>. Acesso em: 6 jul. 2018.

BROUGÈRE, Giles. Jogo e Educação. Porto Alegre: Artes Médicas, 1998.

BUCKINGHAM, David. Crescer na Era das Mídias Eletrônicas. São Paulo: Loyola, 2007.

BUCKINGHAM, David; SCANLON, Margaret. Connecting the Family? 'Edutainment' Websites and Learning in the Home. Education, Communication 
and Information, v. 4, n. 2/3, p. 271-291, 2004. Disponível em: <http://www.tandfonline.com/doi/abs/10.1080/1463631042000288282>. Acesso em: 25 ago. 2018.

BUCKINGHAM, David. Cultura Digital, Educação Midiática e o Lugar da Escolarização. Educação \& Realidade, Porto Alegre, v. 35, n. 3, p. 37-58, set./dez. 2010. Disponível em: http://seer.ufrgs.br/educacaoerealidade/article/view/13077. Acesso em: 10 ago. 2018.

COMITÊ GESTOR DA INTERNET NO BRASIL. TIC Kids Online Brasil 2017: pesquisa sobre o uso da internet por crianças e adolescentes. São Paulo: Comitê Gestor da Internet no Brasil, 2018. Disponível em: <http://www.cetic.br>. Acesso em: $1 .^{\circ}$ set. 2019.

COMITÊ GESTOR DA INTERNET NO BRASIL. TIC Kids Online Brasil 2015: pesquisa sobre o uso da internet por crianças e adolescentes. São Paulo: Comitê Gestor da Internet no Brasil, 2016. Disponível em: <http://www.cetic.br $>$. Acesso em: $1 .^{\circ}$ set. 2018.

CHRISTENSEN, Pia; ALLISON, James (Org.). Investigação com Crianças - perspectivas e práticas. Porto: Paula Frassinetti, 2005.

FACER, Keri; FURLONG, John; FURLONG, Ruth; SUTHERLAND, Rosamund. Constructing the Child Computer User: from public policy to private practices. British Journal of Sociology of Education, v. 22, n. 1, p. 91-108, 2001. Disponível em: <http://dx.doi.org/10.1080/01425690123324>. Acesso em: 10 jul. 2018.

FEENBERG, Andrew. O Que é a Filosofia da Tecnologia? In: CONFERÊNCIA PARA ESTUDANTES UNIVERSITÁRIOS DE KOMAMBA. jun. 2003, 'What is philosophy of technology?. Anais... Tradução de Agustín Apaza, com revisão de Newton Ramos de Oliveira, 2003. Disponível em: <http://www.sfu.ca/ andrewf/Feenberg_OQueEFilosofiaDaTecnologia.pdf $>$. Acesso em: $1^{\circ}$ set. 2018.

FELIPE, Jane. 'Vinde a mim as criancinhas': pedofilização e a construção de gênero nas mídias contemporâneas. In: PELÚCIO, Larissa; SOUZA, Luis Antonio Francisco; MAGALHÃES, Bóris Ribeiro; SABATINE, Thiago Teixeira (Org.). Olhares Plurais para o Cotidiano: gênero, sexualidade e mídia. Marília: Oficina Universitária; São Paulo: Cultura Acadêmica, 2012.

FERNANDES; Natália; MARCHI, Rita de Cássia. A Participação das Crianças nas Pesquisas: nuances a partir da etnografia e na investigação participativa. Revista Brasileira de Educação, v. 25, Rio de Janeiro, 2020. Disponível em <http://www. scielo.br/scielo.php?script=sci_arttext\&pid=S1413-24782020000100600\&lng=pt $\& n r m=i s o>$. acesso em 20 ago. 2020

GEE, James. What Videogames Have to Teach Us about Learning and Literacy. Nova York: Palgrave Macmillan, 2003.

GIDDENS, Anthony; SUTTON, Philip. Conceitos Essenciais da Sociologia. São Paulo: Editora da Unesp, 2016.

HADDON, Leslie. Information and Communication Technologies in Everyday Life. Oxford: Berg, 2004.

JAMES, Allison; JENKS, Chris; PROUT, Alan. Theorising Childhood. Cambridge: Polity, 1998

LIVINGSTONE, Sonia. Internet Literacy: a negociação dos jovens com as novas oportunidades on-line. Matrizes, v. 4, n. 2, p. 11-42, 2011. Disponível em: <http://www.revistas.usp.br/matrizes/article/view/38290/41112>. Acesso em: 10 out. 2016.

LIVINGSTONE, Sonia; KIRWIL, Lucyna; PONTE, Cristina; STAKSRUD, Elisabeth. Em suas Próprias Palavras: o que preocupa as crianças on-line? In: MACE- 
DO, Xavier Nunes; PIRES, David Ulisses Brasil Simões; ANJOS, Fernanda Alves (Org.). Classificação Indicativa e Novas Mídias. Brasília: Ministério da Justiça/ Secretaria Nacional de Justiça, 2014.

LIVINGSTONE, Sonia; MASCHERONI, Giovanna; DREIER, Michael; CHAUDRON, Sthephane; LAGAE, Kaat. How Parentes of Young Children Manage Digital Devices at Home: the role of income, educationand parental style. Londres: EU Kids Online, LSE, 2015. Disponível em: <http://www.lse.ac.uk/media@ lse/research/EUKidsOnline/EUKidsIV/PDF/Parentalmediation.pdf $>$. Acesso em: 2 mar. 2017.

LOUREIRO, Carla Cristiane. 'Eu aprendo a brincar de mais coisas que eu não sabia!': crianças e videogames numa brinquedoteca escolar. 2017. 250 p. Tese (Doutorado em Educação). Programa de Pós-Graduação em Educação, Universidade do Estado de Santa Catarina (UDESC. Florianópolis, 2017.

MARCHI, Rita de Cássia. Os sentidos (paradoxais) da infância nas Ciências Sociais: um estudo de sociologia da infância crítica sobre a 'não-criança' no Brasil. 2007. 308 p. Tese (Doutorado em Sociologia Política). Programa de Pós Graduação em Sociologia Política, Universidade Federal de Santa Catarina (UFSC), Florianópolis, 2007.

PEREIRA, Rita Ribes. Entre o (En)canto e o Silêncio das Sereias: sobre o (não) lugar da criança na cibercultura. Childhood \& Philosophy, Rio de Janeiro, v. 9, n. 18, p. 319-343, jul./dez. 2013. Disponível em: <http://www.e-publicacoes.uerj. br/index.php/childhood/article/view/20660>. Acesso em: 2 ago. 2018.

PONTE, Cristina. Lisboa (Portugal). Entrevista. 19 mai. 2016.

PRENSKY, Marc. Não me Atrapalhe, Mãe - Eu estou aprendendo! São Paulo: Phorte, 2010.

PRETTO, Nelson De Luca. Educações, Culturas e Hackers: escritos e reflexões. Salvador, Bahia: Edufba, 2017.

QVORTRUP, James. A Infância Enquanto Categoria Estrutural. Educação e Pesquisa, São Paulo, v. 36, n. 2, p. 631-644, ago. 2010. Disponível em: <http://www. scielo.br/scielo.php?script=sci_arttext\&pid=S1517-97022010000200014\&lng=en \&nrm=iso>. Acesso em: 10 jun. 2018.

SARMENTO, Manuel; PINTO, Manuel. As Crianças: contextos e identidades. Braga: Centro de Estudos da Criança/ Universidade do Minho, 1997.

SARMENTO, Manuel. Visibilidade Social e Estudo da Infância. In: VASCONCELLOS, Vera; SARMENTO, Manuel (Org.). Infância (In)visível. Araraquara: Junqueira \& Marin, 2007. P. 25-49.

SARMENTO, Manuel. A Reinvenção do Ofício de Criança e de Aluno. Atos de Pesquisa em Educação, FURB, Blumenau, v. 6, n. 3, p. 581-602, set./dez., 2011. Disponível em: <www.furb.br>. Acesso em: 25 ago. 2018.

SARMENTO, Manuel. Radicalização da Infância na Segunda Modernidade. Para uma sociologia da infância crítica. Configurações, Porto, n. 4, p. 91-113, 2008. Disponível em: <https://configuracoes.revues.org/498>. Acesso em: 2 ago. 2018.

TURKLE, Sherry. A Vida no Ecrã: a identidade na era da internet. Lisboa: Relógio D’Água, 1997.

VALENTINE, Gil; HOLLOWAY, Sarah. Cyberkids? Exploring children's identities and social networks in on-line and off-line worlds. Annals of the In: ASSOCIATION OF AMERICAN GEOGRAPHERS, 2002. Anais... v. 92, n. 2. P. 302-319. 
Disponível em: <http://onlinelibrary.wiley.com/doi/10.1111/1467-8306.00292/ abstract>. Acesso em: 2 ago. 2018.

VINCENT, Jane. Mobile Opportunities: exploring positive mobile opportunities for European children. Londres: POLIS, LSE, 2015. Disponível em: <http:// eprints.lse.ac.uk/61015/>. Acesso em: 6 jul. 2018.

Carla Cristiane Loureiro é doutora em Educação. Professora dos Anos Iniciais do Colégio de Aplicação da UFSC (CA/UFSC).

ORCID: http://orcid.org/0000-0001-8958-7503

E-mail: carlacrisloureiro@gmail.com

Rita de Cássia Marchi é doutora em Sociologia Política (UFSC-PARIS V) e pós-doutora em Estudos Sociais da Criança. Professora pesquisadora do Mestrado e Doutorado em Educação e do Departamento de Ciências Sociais e Filosofia da Universidade Regional de Blumenau (FURB).

ORCID: http://orcid.org/0000-0002-3408-2732

E-mail:rt.mc@bol.com.br

Editor-responsável: Fabiana de Amorim Marcello

Este é um artigo de acesso aberto distribuído sob os termos de uma Licença Creative Commons Atribuição 4.0 Internacional. Disponível em: <http:// creativecommons.org/licenses/by/4.0>. 